\title{
Maintaining Adequate Nutrition, Not Probiotic Administration, Prevents Growth Stunting and Maintains Skeletal Muscle Protein Synthesis Rates in a Piglet Model of Colitis
}

\author{
SCOTT V. HARDING, OLASUNKANMI A. J. ADEGOKE, KEELY G. FRASER, ERROL B. MARLISS, STÉPHANIE CHEVALIER, \\ SCOT R. KIMBALL, LEONARD S. JEFFERSON, AND LINDA J. WYKES
}

\begin{abstract}
School of Dietetics and Human Nutrition [S.V.H., K.G.F., L.J.W.], McGill University, Montreal, Quebec, Canada H9X 3V9; McGill Nutrition and Food Science Centre [O.A.J.A., E.B.M., S.C.], MUHC/Royal Victoria Hospital, Montreal, Quebec, Canada H3A 1A1; Department of Cellular and Molecular Physiology [S.R.K., L.S.J.], Pennsylvania State University, Hershey, Pennsylvania 17033
\end{abstract}

\begin{abstract}
Malnutrition and cytokine-induced catabolism are pervasive in children with inflammatory bowel diseases (IBD), however, the benefits of aggressive nutrition support or of probiotics on nutrient and functional deficiencies and growth remain unclear. Piglets with dextran sulfate (DS)-induced colitis consuming a 50\% macronutrient restricted diet (C-MR) were compared with those receiving probiotics $(\mathrm{C}-\mathrm{MRP})$ or adequate nutrition $(\mathrm{C}-\mathrm{WN})$ and with healthy well-nourished controls (REF). C-WN versus REF had reduced growth $(-34 \%$ chest circumference and $-22 \%$ snout-to-rump length gain) and a tendency toward lesser weight gain, but no differences in skeletal muscle protein fractional synthesis rates (FSR) or initiation of translation via the mTOR pathway were observed. Compared with C-WN, the C-MR and C-MRP piglets had lower weight gain, growth, and skeletal muscle FSR, and lower phosphorylated p70S6K1 with higher eIF4E*4E-BP1, indicative of reduced initiation of protein translation. Finally, plasma leucine concentrations were positively correlated with weight and phosphorylated p70S6K1, whereas negatively correlated with eIF4E*4E-BP1. In conclusion, reductions in weight gain, growth, protein turnover, skeletal muscle FSR, and initiation of protein translation with moderate macronutrient restriction in colitis are not ameliorated by probiotic supplementation. However, maintaining adequate nutrient intake during colitis preserves whole body protein metabolism, but growth remains compromised. (Pediatr Res 67: 268-273, 2010)
\end{abstract}

$\mathrm{D}$ ecreased growth velocity because of compromised nutritional status occurs in approximately one third of children with inflammatory bowel disease (IBD) and frequently precedes the diagnosis (1-3). Despite other advances in the treatment of pediatric IBD, maintaining nutritional status and preventing growth stunting remain challenges (4). Changes in nutritional status that cause stunting are primarily due to dietary restriction in response to abdominal pain and/or ele-

Received July 13, 2009; accepted November 7, 2009.

Correspondence: Linda J. Wykes, Ph.D., School of Dietetics and Human Nutrition, McGill University, 21111 Lakeshore, Montreal, QC, Canada H9X 3V9; e-mail: linda.wykes@mcgill.ca

Supported by Natural Sciences and Engineering Research Council of Canada (L.J.W.) and in part by Canadian Institutes of Health Research grant MOP62889 (E.B.M.) and NIH grant DK15658 (L.S.J.).

Current address: Olasunkanmi A. J. Adegoke, School of Kinesiology and Health Science, York University, Toronto, Canada, Scott V. Harding, Richardson Centre for Functional Foods and Nutraceuticals, University of Manitoba, Winnipeg, Canada, and Keely G. Fraser, le Centre de Recherche, le Centre Hospitalier de l'Université de Montréal, Montreal, Canada. vated cytokines (5). When compromised nutrition becomes chronic, delayed menarche in females and permanent stunting in both genders are likely (6). Not only is energy intake decreased, but resting energy expenditure is also higher in IBD compared with nutrient restriction alone, such as in anorexia nervosa $(7,8)$. Under these dietary and metabolic conditions an amino acid deficit causes the mobilization of skeletal muscle protein to provide amino acids both for energy substrate and to supply the essential amino acid demand (9). A net tissue protein catabolic state ensues, exacerbated by the concurrent increase in acute phase protein synthesis (PS). All these factors contribute to muscle wasting and loss of muscle strength, persisting to some extent even in disease remission (10). These are even more serious in children and adolescents, whose muscle mass should be increasing.

A variety of means, including anabolic pharmaceuticals and/or enteral nutrition supplementation (11) can be used to prevent loss of lean mass. The goal of these strategies is to sustain an anabolic state by stimulating PS and minimizing proteolysis. From the perspective of skeletal muscle, these approaches stimulate the initiation of protein translation through the mTOR pathway, reduce proteolytic activity (especially ubiquitin-mediated proteolysis), or both. This cellular effect would then translate into increases in skeletal muscle fractional synthesis rate (FSR) and maintenance of normal growth and muscle mass.

Enteral nutrition could be effective in preventing muscle wasting and growth stunting in IBD by either increasing the insulin-mediated cellular signals, which initiate PS or a direct increase in nutrient availability. Anabolic effects of elevated plasma amino acids, specifically leucine, are well established and have been demonstrated in both healthy $(12,13)$ and "septic" piglets (14). Furthermore, a recent clinical study has shown that hyperinsulinemia and disease remission in adults with Crohn's disease or ulcerative colitis are correlated (15).

\footnotetext{
Abbreviations: C-MR, colitis with macronutrient restriction; C-MRP, colitis with macronutrient restriction and probiotics; C-WN, well-nourished with colitis; DS, dextran sulfate; FSR, fractional synthesis rate; IBD, inflammatory bowel disease; LD, longissimus dorsi; PS, protein synthesis; REF, healthy well-nourished reference piglets
} 
Therefore, despite an energy deficit maintaining growth and PS may be possible with a constant supply of nutrients.

We previously demonstrated in the same piglets used in this study that probiotic supplementation increased hepatic PS and synthesis of albumin, but did not affect disease severity or PS in the colon itself (16). On the basis of the unanticipated finding of stimulated hepatic PS, we aimed to explore whether probiotics would elicit a similar anabolic effect in skeletal muscle to mitigate muscle wasting associated with reduced food intake and inflammation in IBD. Others have shown that probiotic supplementation is a potential adjunctive therapy for both adult and pediatric IBD (17-19). However, most clinical studies of probiotics have focused on controlling symptoms and inducing remission but not nutritional status.

Consequently, this study examined the effect of constant enteral feeding at adequate macronutrient intakes, 50\% macronutrient requirement, or $50 \%$ requirement with probiotic supplementation in the face of an acute colitis challenge. We used the constant feeding approach to raise both insulin and amino acid concentrations. Sustained stimulus of insulin and leucine-mediated cell signaling was postulated to stimulate net anabolic cellular processes. Therefore, our hypotheses were that 1) maintenance of adequate nutrient intakes would prevent growth impairment and maintain muscle PS rates and 2) probiotic administration would not attenuate the decrease in growth and muscle PS in response to food restriction, in a piglet model of colitis.

\section{METHODS AND MATERIALS}

Animals and study protocol. Piglets $(n=32 ; 5$ - to 7-d old; Yorkshire $\times$ Landrace) were randomized to four treatment groups for the $14 \mathrm{~d}$ study. Three groups received dextran sulfate (DS) $\left(1 \mathrm{~g} \cdot \mathrm{kg}^{-1} \cdot \mathrm{d}^{-1}\right)$ to induce colitis: a well-nourished group $(\mathrm{C}-\mathrm{WN})$ receiving $100 \%$ of the macronutrient requirements for growing piglets and two malnourished groups received a 50\% macronutrient restricted diet without (C-MR) or with probiotics (C-MRP). The remaining eight piglets, receiving $100 \%$ of nutritional requirements served as a well-nourished and healthy reference group without colitis (REF). Catheters were implanted in femoral and jugular veins, stomach, and bladder on d $1(16,20,21)$. Constant intragastric feeding was started within $2 \mathrm{~h}$, with full feeding achieved by the morning of $\mathrm{d} 3$. On $\mathrm{d} 2$, probiotic supplementation began in C-MRP piglets. On d 4, DS administration began in colitis groups. The presence of occult blood, with Hemoccult (Beckman Coulter, ON, Canada), after $5 \mathrm{~d}$ of DS administration confirmed colitis. A stable isotope infusion study was conducted in the fed state on d 14 to determine whole body protein turnover and skeletal muscle protein FSR. Colon samples obtained at necropsy were assayed for myeloperoxidase activity as an index of neutrophil infiltration and disease severity (16). The study protocol was approved by the McGill University Animal Care Committee in accordance with the Canadian Council on Animal Care Guidelines.

Probiotics. C-MRP piglets received $450 \times 10^{9} \mathrm{CFU}$ of VSL\#3 (VSL Pharmaceuticals, Gaithersburg, MD) as 1 packet/d in $30 \mathrm{~mL}$ of diet, $15 \mathrm{~mL}$ twice daily). The dose was based on studies in rodents and humans, using body weight (0.73) to scale between metabolic body sizes (22-24).

Diet. Egg albumin and whey protein based diets were formulated in our laboratory as previously described (16). Diets were infused daily over $16 \mathrm{~h}$ (Compat Feeding Pump; Novartis Nutrition, Canada) to deliver $300 \mathrm{~mL} / \mathrm{kg}$ over $24 \mathrm{~h}$ via the gastric catheter to achieve nutritionally adequate energy intakes of $925 \mathrm{~kJ} \cdot \mathrm{kg}^{-1} \cdot \mathrm{d}^{-1}$ for REF/C-WN and $50 \%$ recommended intakes of $461 \mathrm{~kJ} \cdot \mathrm{kg}^{-1} \cdot \mathrm{d}^{-1}$ for C-MR/C-MRP piglets $(25,26)$. Intakes were adjusted daily based on weight, and the $50 \%$ restricted diets were supplemented to maintain the same micronutrient intakes as in REF and C-WN groups to avoid micronutrient deficiencies affecting growth, PS or severity of inflammation.

Growth and weight gain. Snout-to-rump length and chest circumference were measured under anesthesia at the beginning of the study and on d 14 . Body weight was measured daily.
Plasma glucose, insulin, amino acids, urea, and cortisol. Metabolites were measured in plasma collected on d 14 at hour 6 of the tracer infusion. Insulin was measured by RIA for porcine insulin (Linco Research, MO). Glucose was determined by glucose oxidase (GM7 Micro-Stat, Analox Instruments, MA). Amino acids were determined by reverse phase HPLC (Beckman Coulter) after automated precolumn $o$-phthaldialdehyde derivatization (27). Urea and cortisol were measured using an automated clinical biochemistry analyzer (Hitachi model 911, ON, Canada).

Amino acid tracer infusion and analysis. The tracer L-[ring${ }^{2} \mathrm{H}_{5}$ ]phenylalanine (98\% enriched) was given as a primed $(35 \mu \mathrm{mol} / \mathrm{kg})$, constant $\left(35 \mu \mathrm{mol} \cdot \mathrm{kg}^{-1} \cdot \mathrm{h}^{-1}\right)$ infusion over $6 \mathrm{~h}$ in the fed state on $\mathrm{d} 14$. Blood was sampled at baseline and hourly throughout infusion. Longissimus dorsi (LD) and masseter muscles, representing fast-twitch glycolytic and slow-twitch oxidative muscle fibers, respectively, were removed immediately after piglets were killed with sodium pentobarbital. Amino acids (n-propyl ester heptafluorobutyramide derivatives) in plasma and muscle were prepared, as previously described (20). Phenylalanine enrichment was analyzed by negative chemical ionization gas chromatography-mass spectrometry (Hewlett Packard Model 5988A, CA), by monitoring the $[\mathrm{M}-\mathrm{FH}]^{-}$ions at mass to charge ratio 383 and 388 , corresponding to unlabeled and labeled ions, respectively. Tracer:tracee ratios were determined using raw ion abundances and analysis of the tracer and natural abundance of phenylalanine $(16,20)$.

Phenylalanine flux was calculated from dilution of the tracer at plateau in the phenylalanine pool, as we have described (16). Whole body protein turnover was calculated from phenylalanine flux based on the phenylalanine content of protein in piglets $(3.7 \mathrm{~g} / 100 \mathrm{~g})(28)$. The FSRs of mixed proteins in LD and masseter were determined as rate of increase in protein-bound phenylalanine enrichment over the phenylalanine enrichment of the intracellular free pool (20). Phenylalanine enrichment in mixed plasma proteins at baseline was used as a surrogate for baseline or background enrichment in muscle proteins.

Analysis of translation initiation factors and total ubiquitinated proteins. To assess diet and probiotic effects on the activation of translation initiation factors, we examined the phosphorylation of mTOR and of its substrates, p70S6K1 and 4E-BP1, in LD samples only. Frozen LD samples were processed as previously described for analysis of eIF4E*4E-BP1 complex and phosphylated Akt, mTOR, S6K1 and ribosomal protein S6, eIF4E, 4E-BP1 $(27,29,30)$. As an index of ubiquitin mediated-proteolysis, total ubiquitinated protein levels were determined in LD samples by immunoblotting, as previously described (27).

Statistical analysis. All data were analyzed using SPSS version 11.0 (SPSS Inc., Chicago, IL) and reported as mean \pm SEM. Daily weight gain was analyzed by repeated measures ANOVA. Continuous variables were analyzed by one-way ANOVA followed by posthoc least squared difference and Dunnett's test for between group comparisons using C-WN group as the comparison group and $p<0.05$ considered statistically significant. MannWhitney $\mathrm{U}$ test was used to analyze immunoblotting results, with $p<0.05$ considered significant. Pearson correlation analysis was used to determine relationships between plasma leucine and weight gain, phosphorylated p70S6K1 and eIF4E*4E-BP1.

\section{RESULTS}

Weight gain and growth. The C-WN piglets achieved only $66 \%(p<0.03)$ of the chest circumference gain and $78 \%(p<$ 0.05 ) of snout-to-rump length gain of REF piglets. Although weight gain parameters did not reach statistical significance, average daily weight gain (Table 1) of C-WN piglets tended to

Table 1. Growth characteristics in response to nutritional status, colitis and probiotic supplementation

\begin{tabular}{lcccc}
\hline & REF & C-WN & C-MR & C-MRP \\
\hline $\begin{array}{c}\text { Weight gain } \\
\left(\mathrm{g} \cdot \mathrm{kg}^{-1} \cdot \mathrm{d}^{-1}\right)\end{array}$ & $125 \pm 9.1$ & $98.9 \pm 11.1$ & $46.5 \pm 5.6^{*}$ & $47.8 \pm 4.5^{*}$ \\
$\begin{array}{l}\text { Chest circumference } \\
(\% \text { gain })\end{array}$ & $17.6 \pm 2.0^{*}$ & $11.8 \pm 1.5$ & $4.0 \pm 1.0^{*}$ & $3.0 \pm 1.2^{*}$ \\
$\begin{array}{l}\text { Snout-rump length } \\
(\% \text { gain })\end{array}$ & $27.6 \pm 1.6^{*}$ & $21.6 \pm 2.2$ & $19.6 \pm 1.1^{*}$ & $19.3 \pm 2.0^{*}$ \\
\hline
\end{tabular}

Values are means \pm SEM.

$* p<0.05$ vs C-WN. 


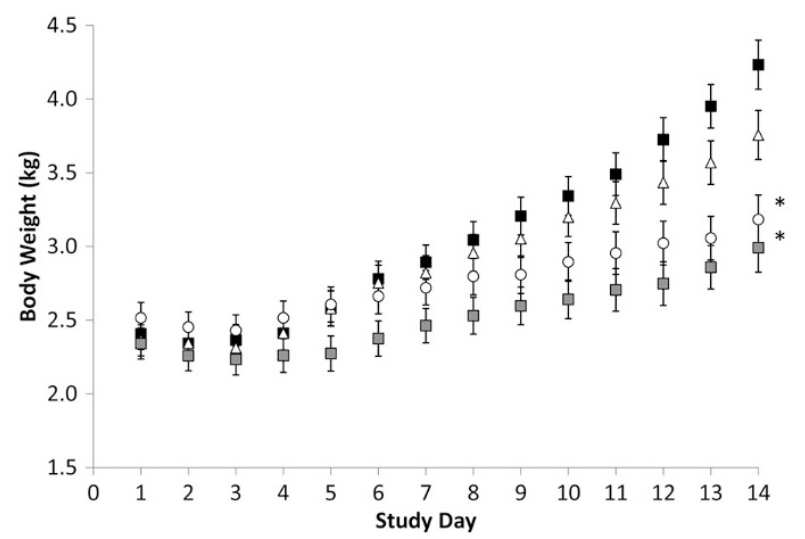

Figure 1. Daily body weights of piglets. REF, black squares; C-WN, open triangles; C-MR, open circles; C-MRP, gray squares. Mean $\pm \mathrm{SEM}, n=8$; ${ }^{*} p<0.05$ (repeated measures ANOVA) vs C-WN.

Table 2. Plasma hormone and metabolite concentrations, phenylalanine flux, whole body protein turnover

\begin{tabular}{|c|c|c|c|c|}
\hline & REF & C-WN & C-MR & C-MRP \\
\hline Glucose $(\mathrm{mmol} / \mathrm{L})$ & $6.4 \pm 0.6$ & $7.1 \pm 0.7$ & $5.3 \pm 0.7$ & $4.8 \pm 0.4^{*}$ \\
\hline Insulin (pmol/L) & $63.2 \pm 18.3$ & $74.7 \pm 29.4$ & $70.6 \pm 27.5$ & $32.0 \pm 10.1$ \\
\hline $\begin{array}{l}\text { Plasma cortisol } \\
\text { (nmol/L) }\end{array}$ & $50.2 \pm 18.0$ & $47.0 \pm 19.8$ & $75.5 \pm 22.0$ & $38.1 \pm 8.6$ \\
\hline $\begin{array}{l}\text { Plasma urea } \\
\qquad(\mu \mathrm{mol} / \mathrm{L})\end{array}$ & $1.48 \pm 0.34$ & $0.97 \pm 0.26$ & $2.99 \pm 0.81^{*}$ & $2.23 \pm 0.59$ \\
\hline $\begin{array}{l}\text { Total amino acids } \\
(\mathrm{mmol} / \mathrm{L})\end{array}$ & $7.57 \pm 0.99$ & $7.63 \pm 1.01$ & $6.49 \pm 1.40$ & $5.28 \pm 0.27$ \\
\hline $\begin{array}{l}\text { Nonessential } \\
\quad(\mathrm{mmol} / \mathrm{L})\end{array}$ & $5.20 \pm 0.71$ & $5.23 \pm 0.66$ & $4.70 \pm 1.1$ & $3.85 \pm 0.23$ \\
\hline Essential (mmol/L) & $2.37 \pm 0.28$ & $2.40 \pm 0.40$ & $1.80 \pm 0.34$ & $1.43 \pm 0.08^{*}$ \\
\hline $\begin{array}{l}\text { Branched chain } \\
(\mathrm{mmol} / \mathrm{L})\end{array}$ & $1.23 \pm 0.09$ & $1.24 \pm 0.15$ & $0.85 \pm 0.20$ & $0.64 \pm 0.05 *$ \\
\hline Aromatic $(\mathrm{mmol} / \mathrm{L})$ & $0.55 \pm 0.09$ & $0.61 \pm 0.11$ & $0.57 \pm 0.09$ & $0.40 \pm 0.03$ \\
\hline $\begin{array}{l}\text { Phenylalanine flux } \\
\qquad\left(\mu \mathrm{mol} \cdot \mathrm{kg}^{-1} \cdot\right. \\
\left.\mathrm{d}^{-1}\right)\end{array}$ & $4169 \pm 385$ & $4063 \pm 156$ & $2571 \pm 249 *$ & $2547 \pm 214^{*}$ \\
\hline $\begin{array}{l}\text { Protein turnover } \\
\qquad\left(\mathrm{g} \cdot \mathrm{kg}^{-1} \cdot \mathrm{d}^{-1}\right)\end{array}$ & $313 \pm 28.9$ & $305 \pm 11.7$ & $193 \pm 18.7 *$ & $191 \pm 16.0^{*}$ \\
\hline
\end{tabular}

Values are means $\pm \mathrm{SEM}$.

$* p<0.05$ vs C-WN.

be lower by $21 \%(p<0.07)$ and total weight gain (Fig. 1$)$ also tended to be lower by $24 \%(p<0.06)$ compared with REF piglets. Macronutrient restriction with colitis substantially reduced average daily and total weight gain and chest circumference by $-53 \%(p<0.001),-53 \%(p<0.001)$, and $-66 \%$ $(p<0.001)$, respectively in C-MR compared with C-WN piglets, with no difference in linear growth. Probiotic supplementation did not attenuate this reduced weight gain or growth. However, weight did not plateau in either macronutrient restricted group (Fig. 1).

Plasma glucose, insulin, cortisol, amino acids, and whole body protein turnover. Reflecting differences in their continuously fed state, glucose was lower in C-MRP than C-WN and insulin tended to be lower (Table 2). Cortisol did not differ, possibly due to diurnal variations and degree of colitis severity. Neither C-WN nor C-MR affected plasma total branched chain, aromatic, essential, nonessential, total (Table 2), or individual amino acid concentrations (Table 3). Similarly, no
Table 3. Individual plasma amino acid concentrations

\begin{tabular}{lcccc}
\hline Amino acid & REF & C-WN & C-MR & C-MRP \\
\hline Taurine & $175 \pm 43$ & $115 \pm 24$ & $112 \pm 27$ & $64 \pm 5$ \\
Aspartate & $63 \pm 21$ & $48 \pm 4$ & $60 \pm 26$ & $34 \pm 2^{*}$ \\
Serine & $464 \pm 130$ & $495 \pm 132$ & $237 \pm 57$ & $166 \pm 14^{*}$ \\
Glutamate & $355 \pm 47$ & $330 \pm 59$ & $301 \pm 88$ & $306 \pm 40$ \\
Glutamine & $735 \pm 142$ & $546 \pm 50$ & $734 \pm 267$ & $458 \pm 32$ \\
Glycine & $1660 \pm 265$ & $1983 \pm 344$ & $1779 \pm 402$ & $1598 \pm 214$ \\
Alanine & $945 \pm 89$ & $1122 \pm 86$ & $913 \pm 139$ & $837 \pm 80^{*}$ \\
Citrulline & $218 \pm 40$ & $222 \pm 37$ & $264 \pm 87$ & $158 \pm 27$ \\
Tyrosine & $204 \pm 16$ & $234 \pm 35$ & $205 \pm 37$ & $146 \pm 15^{*}$ \\
Asparagine & $171 \pm 52$ & $139 \pm 21$ & $91 \pm 25$ & $85 \pm 8^{*}$ \\
Threonine & $422 \pm 95$ & $481 \pm 47$ & $309 \pm 38$ & $283 \pm 30$ \\
Methionine & $138 \pm 26$ & $146 \pm 36$ & $94 \pm 23$ & $75 \pm 4$ \\
Valine & $529 \pm 25$ & $584 \pm 77$ & $423 \pm 91$ & $305 \pm 22^{*}$ \\
Isoleucine & $306 \pm 26$ & $328 \pm 45$ & $210 \pm 54$ & $172 \pm 15^{*}$ \\
Leucine & $358 \pm 55$ & $323 \pm 33$ & $221 \pm 64$ & $166 \pm 16^{*}$ \\
Phenylalanine & $272 \pm 43$ & $315 \pm 66$ & $318 \pm 49$ & $217 \pm 21$ \\
Tryptophane & $57 \pm 19$ & $57 \pm 14$ & $44 \pm 13$ & $37 \pm 3$ \\
Histidine & $41 \pm 8$ & $41 \pm 9$ & $57 \pm 8$ & $41 \pm 8$ \\
\hline
\end{tabular}

Values are means \pm SEM $(\mu \mathrm{mol} / \mathrm{L})$.

$* p<0.05$ vs C-WN.

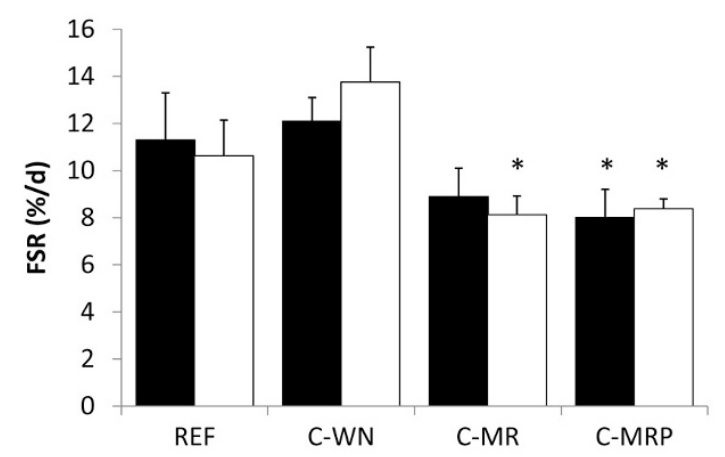

Figure 2. Skeletal muscle mixed protein fractional synthesis rates. LD FSR (black bars) and masseter FSR (white bars). Mean \pm SEM, $n=8 ; * p<0.05$ vs C-WN.

differences in plasma individual or total amino acid concentrations were observed between C-MR and C-MRP piglets. However, plasma aspartate, serine, alanine, valine, isoleucine, leucine, tyrosine, asparagine, total branched chain, and total essential amino acids were lower $(p<0.05)$ in C-MRP compared with C-WN piglets.

Colitis in well-nourished piglets did not affect whole body protein turnover or phenylalanine flux (Table 2). Whole body protein turnover was $\approx 30 \%$ lower $(p<0.05)$ in C-MR and C-MRP versus C-WN. However, plasma urea concentrations were higher in the C-MR $(p<0.05)$ and tended to be higher $(p<0.09)$ in C-MRP compared with C-WN piglets.

Skeletal muscle protein synthesis, translation initiation factors, and ubiquitinated proteins. Skeletal muscle PS in C-WN piglets was not different from REF piglets (Fig. 2). However, compared with C-WN, C-MR piglets tended to have $27 \%$ lower $(p<0.10)$ LD FSR, whereas masseter FSR was $41 \%$ lower $(p<0.05)$. The C-MRP group had 34\% $(p<0.05)$ and $39 \%(p<0.05)$ lower LD and masseter FSR, respectively. Probiotics did not increase FSR of either muscle type compared with C-MR piglets. 
Phosphorylation states of Akt, mTOR, 4E-BP1, p70S6K1, and ribosomal protein $\mathrm{S} 6$ were not affected in $\mathrm{C}-\mathrm{WN}$ versus REF piglets nor was the level of eIF4E*4E-BP1 complex (Fig. $3 A-C$ ). Both C-MR and C-MRP resulted in lower levels of phosphorylated p70S6K1 and higher levels of eIF4E*4E-BP1 complex compared with C-WN $(p<0.05)$. None of these variables differed between C-MR and C-MRP. There were no treatment effects on muscle ubiquitinated protein levels (Fig. 3D).

Plasma leucine correlations. Plasma leucine was positively correlated $(\mathrm{r}=0.46, p<0.02)$ with weight gain $\left(\mathrm{g} \cdot \mathrm{kg}^{-1} \cdot \mathrm{d}^{-1}\right)$ and with phosphorylated p70S6K1 level $(\mathrm{r}=$ $0.45, p<0.04)$ and negatively correlated with eIF4E*4EBP1 complex levels $(\mathrm{r}=-0.55, p<0.006)$ in piglets regardless of treatment (Fig. 4).

\section{DISCUSSION}

The inflammatory stress of colitis in well-nourished piglets resulted in a lower growth rate compared with healthy controls, as manifested by slower gain in weight, chest circumference, and snout-to-rump length. However, there were no corresponding differences in whole body protein turnover, skeletal muscle protein FSR, or the molecular controls of mRNA translation between the C-WN and REF piglets. This suggests that growth was compromised in tissues not studied, such as those of the skeleton and/or other muscles. It is noteworthy that both muscles of differing fiber type distribution responded similarly. Metabolic changes, including stimulated immune and acute phase responses, are likely responsible for redirecting amino acids and energy substrates resulting in the overall growth impairment. If pertinent clinically, our findings point to insidious growth impairment, which may go undetected without regular anthropometric follow-up (31).

Our $50 \%$ macronutrient restriction model was designed to simulate the food avoidance behavior associated with the human disease. Although growth and weight gain were lower in C-MR and C-MRP compared with C-WN, these piglets did continue to gain weight throughout the course of the study. The reduced growth, whole body protein turnover and muscle protein FSR in the restricted piglets were associated with a lesser degree of activation of muscle p70S6K1 and more sequestering of eIF4E into inactive eIF4E*4EBP1 complex, responses that are indicative of downregulation of mRNA translation initiation. This downregulation was not observed in $\mathrm{C}-\mathrm{WN}$ piglets compared with their healthy controls and underscores the importance of adequate nutrition during colitis.

Interindividual variability, related to constant rather than meal feeding, may have precluded demonstration of significant alterations both in upstream signaling (Akt/mTOR) and of ribosomal protein S6 in muscle (32). Providing exogenous amino acids increases PS concurrent with activation of mRNA translation by leucine through the mTOR pathway $(12,13)$, even in a sepsis model (14). We have shown previously that chronic protein deficiency in a piglet model of systemic inflammation (33), and that macronutrient restriction in the piglet colitis model (20) exacerbate decreases in muscle FSR concurrent with the stimulation of plasma PS induced by inflammation. Thus, comparable muscle FSR in C-WN compared with REF piglets and lower FSR in both restricted groups are related to their macronutrient intakes and stress state. Although we examined only one component of the ubiquitin pathway, it is a major determinant of skeletal muscle intracellular proteolysis. The absence of a difference in ubiquitinated proteins across groups is consistent with, but does not confirm, that impaired growth was not predominantly mediated by this proteolytic pathway. It is also possible that the deubiquitinating enzyme USP19, which is induced in atrophying skeletal muscle and stimulated by dexamethasone (34) played a role in mediating the negative balance between muscle PS and proteolysis. However, USP19 has not yet been studied in pigs.
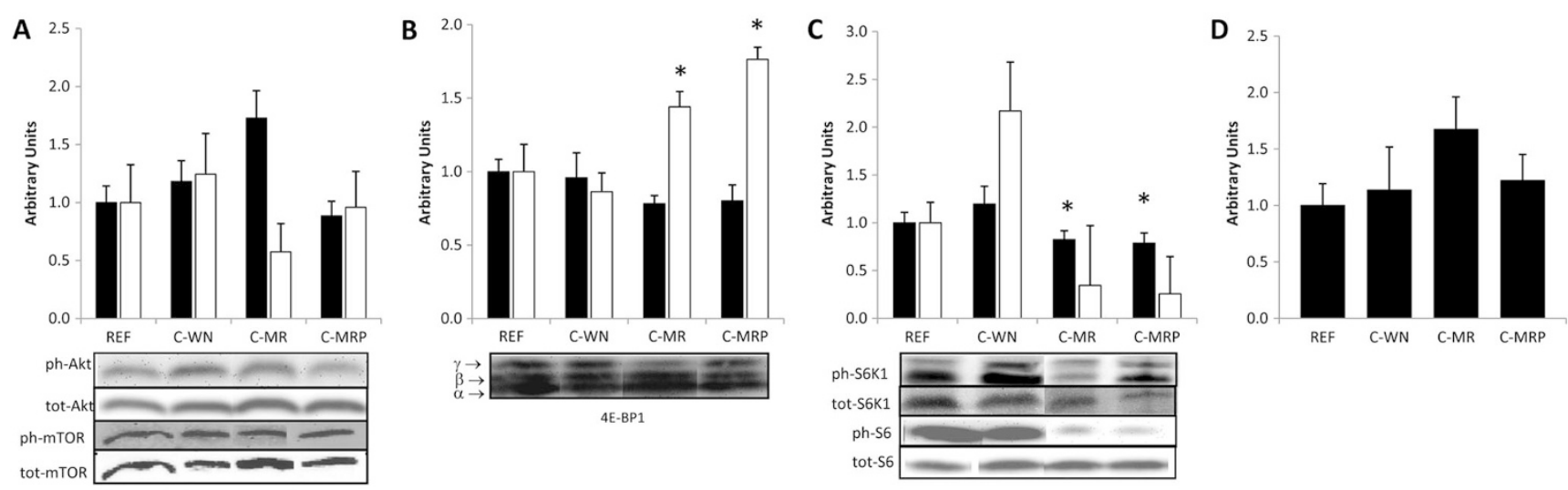

Figure 3. Panels $A-D$, Molecular controls of mRNA translation and ubiquitinated proteins. A, Relative phosphorylated Akt (black bars) and mTOR (white bars). B, Relative phosphorylated 4EBP1 (black bars) and eIF4E*4E-BP1 complex (white bars). C, Relative phosphorylated p70S6K1 (black bars) and ribosomal protein S6 (white bars). D, Relative total ubiquitinated proteins. Mean \pm SEM; $* p<0.05 v s$ C-WN. To generate representative blots shown, SDS-PAGE of proteins for all samples was performed at the same time. Transfer of proteins to membranes, immunoblotting, image capture, and quantitation were done for all samples for each variable at the same time. To align the lanes in the order shown, it was necessary to cut lanes from different parts of the blot and paste them together, without changing image intensity or contrast. 

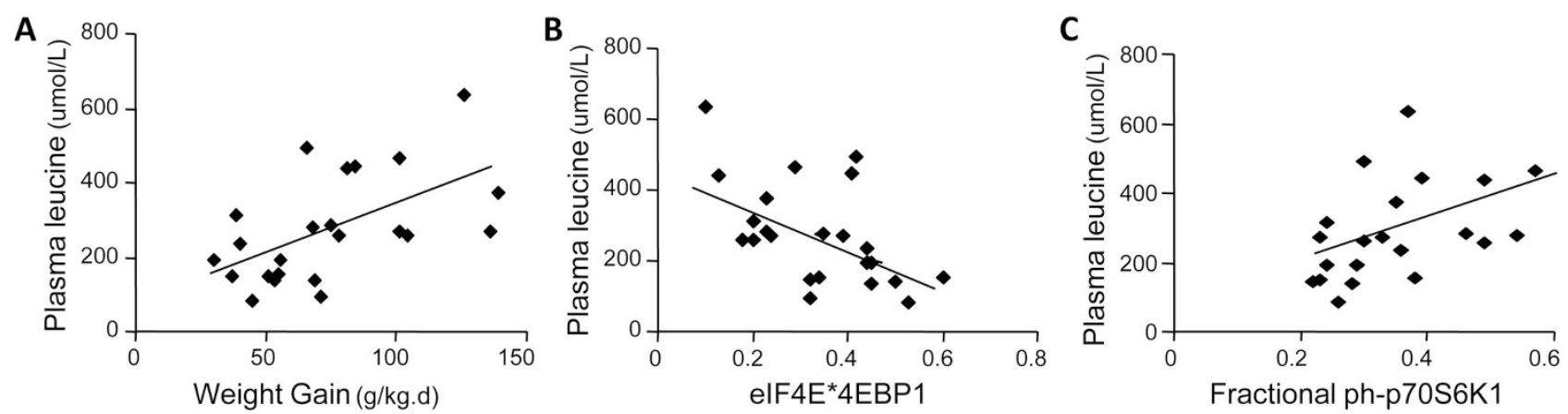

Figure 4. Pearson correlations of plasma leucine concentration ( $\mu \mathrm{mol} / \mathrm{L})$ with $(A)$ weight gain $\left(\mathrm{g} \cdot \mathrm{kg}^{-1} \cdot \mathrm{d}^{-1} ; \mathrm{r}=0.46, p<0.02 ; n=24\right) ;(B) \mathrm{LD}$ muscle eIF4E*4E-BP1 $(\mathrm{r}=-0.55, p<0.006 ; n=24$, and $(C)$ LD muscle phosphorylated p70S6K1 $(\mathrm{r}=0.45, p<0.04 ; n=22)$.

Maintenance of whole body and tissue protein metabolism in C-WN at levels similar to REF suggests a role for constant feeding, possibly mediated by insulin and leucine, to maintain growth during acute inflammation. The trend for higher plasma glucose concentrations in REF and C-WN is perhaps a reflection of greater nutrient provision. Insulin was measured only on d 14 during the tracer infusion study and showed considerable interindividual variability within groups. The insulin assay antibody is known to cross-react with proinsulin, which may differ and contribute to the variability. It is also possible that differences in nutrient absorption, despite constant infusion rates contributed to variable insulin results. Notwithstanding, the absence of greater hyperinsulinemia in REF and C-WN compared with C-MR and C-MRP piglets suggests that insulin levels were sufficient to promote growth and PS and that levels of nutrient provision may limit anabolic responses.

Overall, our data support the hypothesis that provision of nutrients sufficient for growth should improve nutritional status and support critical function in inflammatory conditions $(33,35,36)$. These data in a growing animal model of IBD are relevant given that treatments for pediatric IBD may also have negative impacts on nutritional status and growth. Specifically, glucocorticoids and surgical resection are commonly associated with compromised nutritional status and growth failure (11). In contrast, infliximab has been associated with improved nutritional status (37). Our piglet model could be applied to study the impact of pharmaceuticals on nutritional status and disease severity.

VSL\#3 supplementation is reported to provide symptomatic improvement in selected human trials $(17,18)$ but inconclusive results in animal models of IBD $(23,24,38,39)$. Probiotics did not confer any beneficial changes in growth, weight gain, or whole body protein turnover. We have shown previously in the same piglets that hepatic PS and plasma PS in the C-MRP piglets were comparable with the $\mathrm{C}-\mathrm{WN}$ and $\approx 100 \%$ higher than in C-MR piglets (16). In contrast, muscle PS was lower in macronutrient restricted piglets regardless of probiotic administration. The mechanism for the liver-specific increase in PS remains unclear. Other intriguing differences in the C-MRP piglets are that, unlike the C-MR piglets, they had lower plasma glucose and total essential and branched-chain amino acids. They also differed from C-MR in not having higher serum urea compared with C-WN. It is tempting to speculate that these differences in metabolite concentrations and the similarity in muscle PS between the two groups of restricted piglets might be related to the increased the hepatic and plasma protein FSRs in piglets receiving probiotics given their restricted diet. Alternatively, it is possible that the probiotics may have increased bacterial utilization of amino acids and/or maltodextrin (a prebiotic); however, we did not analyze fecal microflora. The piglet colitis model offers the opportunity to determine whether pre-emptive probiotic treatment would affect disease severity and nutritional status or whether probiotics would influence recovery from inflammatory damage following discontinuation of DS. Both applications would be clinically relevant.

Limitations to this study, in light of our findings, include not measuring metabolite and hormone concentration in plasma at earlier time points. Clamping glucose and amino acid levels would have improved interpretation of insulin/ amino acid regulated pathways. Measuring FSR of other protein pools (e.g. spleen, pancreas, and bone marrow) may have identified them as pools, which respond more robustly to improved nutrition during an inflammatory challenge. In addition, bone density and turnover measures may have provided a more in-depth focus on growth.

In conclusion, this study showed that maintaining adequate nutrition but not supplementation with probiotics prevented growth stunting and maintained skeletal muscle PS in piglets with colitis. When adequate macronutrient intakes were maintained, colitis did reduce growth over $14 \mathrm{~d}$ without compromising whole body protein turnover, skeletal muscle PS, translation initiation, or stimulating ubiquitin-dependent proteolysis in skeletal muscle. Macronutrient restriction slowed weight gain, stunted growth, and reduced whole body protein turnover and signaling for translation initiation in muscle. Probiotic supplementation did not mitigate the lower weight gain, growth, or muscle protein FSR characteristic of the malnourished state despite, or possibly because of, a dramatic stimulation in hepatic PS. Although VSL\#3 probiotic supplementation has shown promising clinical benefits in certain forms of IBD and liver disease, as well as a stimulatory effect on hepatic PS in our model, its benefits may be localized to the enterohepatic tissues. Finally, this study demonstrates the 
need to develop clinical strategies to encourage adequate nutrient intakes during IBD.

Acknowledgments. We thank Dr. Douglas Burrin for discussion and comments relating to this study. We also thank Edward Walker, Brian Lee, Donato Brunetti, Noura Labib, Marie Lamarche, and Ginette Sabourin for laboratory assistance.

\section{REFERENCES}

1. Fisher RL 1999 Wasting in chronic gastrointestinal diseases. J Nutr 129:252S-255S

2. Kanof ME, Lake AM, Bayless TM 1988 Decreased height velocity in children and adolescents before the diagnosis of Crohn's disease. Gastroenterology 95:15231527

3. Seidman E, LeLeiko N, Ament M, Berman W, Caplan D, Evans J, Kocoshis S, Lake A, Motil K, Sutphen J, Thomas D 1991 Nutritional issues in pediatric inflammatory bowel disease. J Pediatr Gastroenterol Nutr 12:424-438

4. Rufo PA, Bousvaros A 2007 Challenges and progress in pediatric inflammatory bowel disease. Curr Opin Gastroenterol 23:406-412

5. Bistrian BR 1999 Role of the systemic inflammatory response in the development of protein-energy malnutrition in inflammatory bowel disease. Nestle Nutr Workshop Ser Clin Perform Programme 2:1-6

6. Kirschner BS 1990 Growth and development in chronic inflammatory bowel disease. Acta Paediatr Scand Suppl 366:98-104; discussion 105

7. Azcue M, Rashid M, Griffiths A, Pencharz PB 1997 Energy expenditure and body composition in children with Crohn's disease: effect of enteral nutrition and treatment with prednisolone. Gut 41:203-208

8. Hill RJ, Cleghorn GJ, Withers GD, Lewindon PJ, Ee LC, Connor F, Davies PS 2007 Resting energy expenditure in children with inflammatory bowel disease. J Pediatr Gastroenterol Nutr 45:342-346

9. Reeds PJ, Fjeld CR, Jahoor F 1994 Do the differences between the amino acid compositions of acute-phase and muscle proteins have a bearing on nitrogen loss in traumatic states? J Nutr 124:906-910

10. Valentini L, Schaper L, Buning C, Hengstermann S, Koernicke T, Tillinger W, Guglielmi FW, Norman K, Buhner S, Ockenga J, Pirlich M, Lochs H 2008 Malnutrition and impaired muscle strength in patients with Crohn's disease and ulcerative colitis in remission. Nutrition 24:694-702

11. Homan M, Baldassano RN, Mamula P 2005 Managing complicated Crohn's disease in children and adolescents. Nat Clin Pract Gastroenterol Hepatol 2.572-579

12. Escobar J, Frank JW, Suryawan A, Nguyen HV, Davis TA 2007 Amino acid availability and age affect the leucine stimulation of protein synthesis and eIF4F formation in muscle. Am J Physiol Endocrinol Metab 293:E1615-E1621

13. Escobar J, Frank JW, Suryawan A, Nguyen HV, Kimball SR, Jefferson LS, Davis TA 2005 Physiological rise in plasma leucine stimulates muscle protein synthesis in neonatal pigs by enhancing translation initiation factor activation. Am J Physiol Endocrinol Metab 288.E914-E921

14. Orellana RA, Kimball SR, Suryawan A, Escobar J, Nguyen HV, Jefferson LS, Davis TA 2007 Insulin stimulates muscle protein synthesis in neonates during endotoxemia despite repression of translation initiation. Am J Physiol Endocrinol Metab 292:E629-E636

15. Valentini L, Wirth EK, Schweizer U, Hengstermann S, Schaper L, Koernicke T, Dietz E, Norman K, Buning C, Winklhofer-Roob BM, Lochs H, Ockenga J 2009 Circulating adipokines and the protective effects of hyperinsulinemia in inflammatory bowel disease. Nutrition 25:172-181

16. Harding SV, Fraser KG, Wykes LJ 2008 Probiotics stimulate liver and plasma protein synthesis in piglets with dextran sulfate-induced colitis and macronutrient restriction. J Nutr 138:2129-2135

17. Bibiloni R, Fedorak RN, Tannock GW, Madsen KL, Gionchetti P, Campieri M, De Simone C, Sartor RB 2005 VSL\#3 probiotic-mixture induces remission in patients with active ulcerative colitis. Am J Gastroenterol 100:1539-1546

18. Huynh HQ, deBruyn J, Guan L, Diaz H, Li M, Girgis S, Turner J, Fedorak R, Madsen K 2009 Probiotic preparation VSL\#3 induces remission in children with mild to moderate acute ulcerative colitis: a pilot study. Inflamm Bowel Dis 15:760768

19. Miele E, Pascarella F, Giannetti E, Quaglietta L, Baldassano RN, Staiano A 2009 Effect of a probiotic preparation (VSL\#3) on induction and maintenance of remission in children with ulcerative colitis. Am J Gastroenterol 104:437-443

20. Mackenzie ML, Warren MR, Wykes LJ 2003 Colitis increases albumin synthesis at the expense of muscle protein synthesis in macronutrient-restricted piglets. J Nut 133:1875-1881

21. Wykes LJ, Ball RO, Pencharz PB 1993 Development and validation of a total parenteral nutrition model in the neonatal piglet. J Nutr 123:1248-1259

22. Gionchetti P, Rizzello F, Venturi A, Brigidi P, Matteuzzi D, Bazzocchi G, Poggioli G, Miglioli M, Campieri M 2000 Oral bacteriotherapy as maintenance treatment in patients with chronic pouchitis: a double-blind, placebo-controlled trial. Gastroenterology 119:305-309

23. Shibolet O, Karmeli F, Eliakim R, Swennen E, Brigidi P, Gionchetti P, Campieri M, Morgenstern S, Rachmilewitz D 2002 Variable response to probiotics in two models of experimental colitis in rats. Inflamm Bowel Dis 8:399-406

24. Madsen K, Cornish A, Soper P, McKaigney C, Jijon H, Yachimec C, Doyle J, Jewell L, De Simone C 2001 Probiotic bacteria enhance murine and human intestinal epithelial barrier function. Gastroenterology 121:580-591

25. Subcommittee on Swine Nutrition Committee on Animal Nutrition Board on Agriculture National Research Council 1998 Models for estimating energy and amino acid requirements. In: Nutrient Requirements of Swine. 10th ed. National Academy Press, Washington, DC, pp 31-46

26. Veum TL, Odle J 2001 Feeding neonatal pigs. In: Lewis AJ, Southern LL (eds) Swine Nutrition. CRC Press, Boca Raton, pp 671-690

27. Adegoke OA, Chevalier S, Morais JA, Gougeon R, Kimball SR, Jefferson LS, Wing SS, Marliss EB 2009 Fed-state clamp stimulates cellular mechanisms of muscle protein anabolism and modulates glucose disposal in normal men. Am J Physiol Endocrinol Metab 296:E105-E113

28. Aumaitre A, Duee PH, Chevalier J, Jung J, Peiniau J 1974 [Amino acid composition of body protein in the piglet between birth and eight weeks of age]. Annales de Zootechnie 23:231-236

29. Kimball SR, Jurasinski CV, Lawrence JC Jr, Jefferson LS 1997 Insulin stimulates protein synthesis in skeletal muscle by enhancing the association of eIF-4E and eIF-4G. Am J Physiol 272:C754-C759

30. Kimball SR, Shantz LM, Horetsky RL, Jefferson LS 1999 Leucine regulates translation of specific mRNAs in L6 myoblasts through mTOR-mediated changes in availability of eIF4E and phosphorylation of ribosomal protein S6. J Biol Chem 274:11647-11652

31. Dziechciarz P, Horvath A, Shamir R, Szajewska H 2007 Meta-analysis: enteral nutrition in active Crohn's disease in children. Aliment Pharmacol Ther 26:795-806

32. Wilson FA, Suryawan A, Orellana RA, Kimball SR, Gazzaneo MC, Nguyen HV, Fiorotto ML, Davis TA 2009 Feeding rapidly stimulates protein synthesis in skeletal muscle of neonatal pigs by enhancing translation initiation. J Nutr 139:1873-1880

33. Jahoor F, Wykes L, Del Rosario M, Frazer M, Reeds PJ 1999 Chronic protein undernutrition and an acute inflammatory stimulus elicit different protein kinetic responses in plasma but not in muscle of piglets. J Nutr 129:693-699

34. Sundaram P, Pang Z, Miao M, Yu L, Wing S 2009 USP19 deubiquitinating enzyme regulates levels of major myofibrillar proteins in L6 muscle cells. Am J Physiol Endocrinol Metab 297:E1283-E1290

35. Lecleire S, Hassan A, Marion-Letellier R, Antonietti M, Savoye G, Bole-Feysot C Lerebours E, Ducrotte P, Dechelotte P, Coeffier M 2008 Combined glutamine and arginine decrease proinflammatory cytokine production by biopsies from Crohn's patients in association with changes in nuclear factor-kappaB and p38 mitogenactivated protein kinase pathways. J Nutr 138:2481-2486

36. Jahoor F, Wykes LJ, Reeds PJ, Henry JF, del Rosario MP, Frazer ME 1995 Protein-deficient pigs cannot maintain reduced glutathione homeostasis when subjected to the stress of inflammation. J Nutr 125:1462-1472

37. Wiese D, Lashner B, Seidner D 2008 Measurement of nutrition status in Crohn's disease patients receiving infliximab therapy. Nutr Clin Pract 23:551-556

38. Gaudier E, Michel C, Segain JP, Cherbut C, Hoebler C 2005 The VSL\# 3 probiotic mixture modifies microflora but does not heal chronic dextran-sodium sulfateinduced colitis or reinforce the mucus barrier in mice. J Nutr 135:2753-2761

39. Di Giacinto C, Marinaro M, Sanchez M, Strober W, Boirivant M 2005 Probiotics ameliorate recurrent Th1-mediated murine colitis by inducing IL-10 and IL-10dependent TGF-beta-bearing regulatory cells. J Immunol 174:3237-3246 